\title{
A CCL and COCA-Based Contrastive Study of LIFE Metaphor in Chinese and English
}

\author{
Shifang Zhou ${ }^{1} \&$ Xiangyong Jiang ${ }^{1}$ \\ ${ }^{1}$ Foreign Languages College, Jiangxi Normal University, Nanchang, China \\ Correspondence: Xiangyong Jiang, Foreign Languages College, Jiangxi Normal University, Jiangxi, China. \\ E-mail: xiangyongjiang@163.com
}

Received: June 6, 2020 Accepted: July 16, 2020 Online Published: July 21, 2020

doi:10.5539/ells.v10n3p62 URL: https://doi.org/10.5539/ells.v10n3p62

\begin{abstract}
This paper analyzes universalities and variations of LIFE metaphor via qualitative and quantitative analysis of data retrieved from two authoritative, general, and monolingual corpora-Center for Chinese Linguistics (CCL) and Corpus of Contemporary American English (COCA) in Chinese and English. The study aims to explore the universalities and variations of LIFE metaphor in Chinese and English on the one hand, further the hidden reasons for the universalities and variations on the other. Results reveal that source domains like JOURNEY/VOYAGE, FOOD, WAR, DREAM, BOOK are employed to conceptualize LIFE both in Chinese and English justifying the universality of conceptual metaphor, which can be ascribed to Chinese and American people's common bodily experience, common knowledge and experience about the world, common social and cultural experience. However, the frequency of conceptualizing FOOD, WAR, DREAM, BOOK is different, and the potential universal metaphors like FOOD show differences in their specific details. Besides, unique source domains are used for a particular culture (OPERA in Chinese). Different socio-cultural contexts, differential memory, Chinese and Americans' different outlooks on life may account for LIFE metaphor's cross-cultural variation.
\end{abstract}

Keywords: life, conceptual metaphor, corpus-based method, contrastive study

\section{Introduction}

Life, as one of the most important philosophical propositions, has been a hot topic frequently studied by philosophers, historians, and litterateurs since ancient times. To some extent, our actions and experiential events can be reasonably accounted for by understanding the "meaning" of life. Although the concept of life is commonly mentioned in our daily life, the true meaning of life cannot be expressed in a few words. In other words, life as an abstract concept does not have a clear and comprehensive definition. However, the concept of life can be externalized by means of metaphor in a cognitive approach, such as LIFE IS A JOURNEY. In this way, our understanding of life can be significantly deepened.

Since George Lakoff and Mark Johnson published Metaphors We Live By in 1980, metaphor is no longer regarded merely as a linguistic device but a cognitive phenomenon. Metaphor is pervasive in everyday life, not just in language but in thought and action (Lakoff \& Johnson, 1980, p. 4). It is all-pervasive to our thinking. As a universal cognitive process, metaphor plays an essential role in shaping our understanding of a daily event. Studying metaphors can help find out the hidden sides of one's mind and culture. What was then known about such ubiquitous metaphor is Conceptual Metaphor Theory (henceforth CMT). Lakoff and Johnson (1980, p. 5) note that "the essence of metaphor is understanding and experiencing one kind of thing in terms of another". In other words, the more abstract concepts (e.g., LIFE) are understood in terms of the more concrete concepts (e.g., JOURNEY), resulting in the conceptual metaphor LIFE IS A JOURNEY. As Kövecses (2002, p. 12) puts it, "to know a conceptual metaphor is to know the set of mappings that applies to a given source-target pairing". Conceptual metaphors are pervasive in language. For example, there are many daily expressions about the conceptual metaphor LIFE IS A JOURNEY, such as looking back on the road, striving to reach our destination in life, be at a crossroads, etc. It is argued that language is a convenient guide for cognitive linguistics to detect the meaning and form of our conceptual system (Langacker, 1987; Lakoff, 1987, as cited in Kövecses, 2015). Lakoff (1993) revealed that metaphorical expressions were a unidirectional mapping through cognitive domains. Porat and Shen (2017) also illustrated that the mapping orientation of metaphorical expressions from the source 
domain to the target domain arises from the conceptual links between the members.

Metaphor is the main mechanism for people to understand abstract concepts. According to Lakoff (1992), some metaphorical concepts seem to be universal, while others are culturally specific to some degree. Among those metaphorical concepts, a massive number of investigations have been done in the domain of emotion (Kövecses, 1986, 1988, 1990), color (Bottomley \& Doyle, 2006; Lan \& Macgregor, 2009), morality (Johnson, 1992), thought (Johnson, 1987; Jäkel, 1995), society (Kövecses, 1994), events and actions (Lakoff, 1993, 1994), and time (Fauconnier \& Turner, 2008). Some researches on LIFE metaphor have also been done as follows.

Lakoff (1994) has provided some examples in English for the LIFE IS A JOURNEY metaphor. He described the coherence of inference in the Event Structure Metaphor and also the inherence of this LIFE metaphor. Lakoff (1999) further indicated how the complex metaphor LIFE IS A PURPOSEFUL JOURNEY is formed by primary metaphors and image schemas. Winter (1995, p. 235) analyzed the LIFE IS A JOURNEY metaphor and implied that some metaphorical mappings or ontological correspondence might be included. Katz and Taylor (2008) provided a more in-depth insight into the sole conceptual metaphor LIFE IS A JOURNEY.

Nevertheless, conceptualizing LIFE as a JOURNEY is but one possible way to understand LIFE. There are all kinds of metaphors concerning LIFE, which understand LIFE metaphorically via a variety of source concepts. George Lakoff and Mark Turner (1989, pp. 2-25) have conducted a detailed study on LIFE metaphor. They pointed out that there are a great many different source concepts that enable us to make sense of LIFE, such as PLAY, BURDEN, STORY, BUILDING, ADVENTURE, GAMBLING GAME, etc. These different source concepts all focused on different aspects of life, leading to different inferences. However, they did not elucidate these metaphors in detail.

Various LIFE metaphors are introduced in different materials, ranging from literary works to advertisements, games, and biographies. In More than Cool Reason: A field guide to poetic metaphor (Lakoff \& Turner, 1989), metaphorical conceptualizations of LIFE were mostly examined within the scope of poems. Yu (2009) introduced the LIFE IS A JOURNEY, and LIFE IS A STAGE metaphor in an educational advertisement. He analyzed how to express the central theme through dynamic visual, auditory, and verbal expressions. Kromhout \& Forceville (2013) investigated LIFE IS A JOURNEY metaphor in three videogames. The schema of source-path-goal is applied in this study, which contributed to expanding the conceptual metaphor theory into the field of videogames. Bystrov (2014) studied the LIFE IS A STORY metaphor in biographical narration, in which the mathematical model fractal is applied. He claimed that the conceptual fractal metaphor made the traditional conceptual metaphor more flexible and dynamic, which further renewed its ability of self-development and self-improvement.

There are also LIFE metaphors investigated from the perspective of culture, highlighting the influence of culture on the formation and function of metaphor. As a particular cultural product, metaphor also provides us with some useful social information. Ching (1993) explored the pervasive LIFE IS PLAYING A GAME metaphor in America. He argued that the popularity of this metaphor was due to the prototypical person and masculinity in American culture. Liang (2010) analyzed LIFE IS A DIET metaphor in Chinese and unveiled what influential role Chinese dietetic culture plays in life. He deemed that examining LIFE IS A DIET metaphor in Chinese is beneficial for us to learn Chinese culture. Wang (2011) studied the relation between the metaphorical conceptualization of wine and Chinese culture through analyzing the LIFE IS WINE metaphor. Yu and Jia (2016) conducted a quantitative and qualitative analysis of the LIFE IS AN OPERA metaphor in Chinese. They believed that both the LIFE IS AN OPERA metaphor in Chinese and the LIFE IS A PLAY metaphor in English are sublevel versions of LIFE IS A SHOW.

Some researchers have also associated LIFE metaphor with people's outlooks and values. Researches on which LIFE metaphor people prefer to have shown that people's different preferences are considered as a sign of people's different attitudes towards life. McMullen and Conway (2002) found that there were four dominating particular metaphors among Canadians diagnosed with severe depression when discussing their condition: metaphors related to darkness, weight, "feeling blue", and especially descent. Cross (2007) explored the LIFE IS AN ENTERTAINMENT metaphor. He regarded it as the primary root metaphor of talented youth in the United States today, mainly caused by technological change, cultural influence, and psychological development. Bochaver and Fenko (2010) compared the metaphors of 20 Russian celebrities interviewed for their achievements in popular magazines with the metaphor of 20 non-celebrity Russians seeking psychological help. Those psychological help-seekers indicated LIFE IS DEATH in their narrative, while the celebrities tended to describe life as a purposeful journey. Through a structured questionnaire, Hoffman (2015) analyzed the LIFE metaphor of 60 Colombian college students in a leadership program to explore their core values. The results 
showed that their LIFE metaphors were mainly active, individualistic, and affectively positive, which could strongly impact their motivation and decision-making. Metaphor analysis has also been found useful as a personality indicator that can be used to measure personality traits like extroversion, optimism, and locus of control (McConnell et al., 1993).

Zoltán Kövecses (2010) explained why the same target domain (e.g., LIFE) is understood through a set of different source domains. The reason is that a single source concept cannot cater to all aspects of the target concept. Then the question arises: what motivates people to choose one metaphor over the others? Kövecses (2015) elaborated it in Where Metaphors Come from: Reconsidering Context in Metaphor. It is claimed that the metaphorical conceptualizations arise from "contextual influence", which refers to several motivational forces, such as the immediate physical environment, the social setting, the cultural setting, differential memory, and differential concerns and interests. However, which of these motivational forces play a more crucial role in understanding the concept of LIFE?

The above researches have made significant contributions to the study of LIFE metaphor. A variety of metaphors concerning LIFE were discussed, which helps us better understand the source of their existence. The studies of LIFE metaphor from the perspective of culture showed that metaphor, as a product of human culture, could also influence us in turn. As for the researches connecting LIFE metaphor with human values and life outlooks, it further reveals the close relationship between the human mind and language. However, the existing researches on LIFE metaphor are still far from satisfactory. First, previous studies on LIFE metaphor are restricted to simply introduce different LIFE metaphors from different aspects such as LIFE IS A JOURNEY, LIEF IS A PLAY, etc. Although there are studies on introducing specific LIFE metaphor from a cultural perspective, much is done at the literary level rather than at the cognitive level. Second, specific LIFE metaphors investigated from a cultural perspective are mainly introduced from a culture. A comparative analysis of LIFE metaphors between different languages, especially the cross-cultural metaphorical variation concerning LIFE between Chinese and English, has not been thoroughly investigated yet. Third, as for the research methodology, the data or examples of previous studies are from a particular single resource (e.g., literary works, advertisements, biographies, etc.), and most of the previous researches are introspective and mainly based on theoretical explanations. However, the evidence that cognitive linguistics should rely on is not only introspective but also includes more empirical evidence such as the results of psycholinguistic tests, language acquisition data, diachronic and synchronic data (either elicited from native speakers or corpus data) (Brdar-Szabo, Rita, \& Mario Brdar, 2012). Therefore, they fail to be representative, comprehensive, and convincing.

In this paper, we attempt to conduct a systematic analysis of the linguistic manifestation of the LIFE metaphor in Chinese and English from the perspective of CMT. Both the quantitative and qualitative methods are used in the process of analyzing data from two corpora. The two corpora are respectively Center for Chinese Linguistics, Peking University (henceforth CCL), and Corpus of Contemporary American English (henceforth COCA). The aim of the present research is twofold. On the one hand, it aims to explore the similarities and differences in understanding LIFE metaphor in Chinese and English, especially the cross-culturally metaphorical variations reflected. On the other hand, it is essential for us to further the hidden reasons that result in the metaphorical language variation and dig out the life outlook which guides the process of understanding and imagination. Our study is novel on several accounts. This paper makes a comparative analysis of the linguistic manifestation of the LIFE metaphor in Chinese and English based on CMT from a cognitive perspective, rather than merely focusing on specific life-metaphor from a literary perspective. The empirical corpus-based methodology can get us rid of the limitations of intuition as much as possible and further ensures the objectivity, comprehensiveness, and reliability of data by providing us with authentic language materials. In addition, the corpus can also provide us with a variety of information (e.g., genre, era, region, etc.), which is conducive to investigating language variations and conducting a quantitative analysis of big data and multiple factors. This paper not only explores the similarities and differences in the metaphorical conceptualization of LIFE but also talks about the factors and reveals the different life values which help the formation of life outlook and the understanding of life essence.

The structure of the paper is as follows: After the introduction, Section 2 describes the methodology of the research. Section 3 enters into some quantitative and qualitative analyses of the corpus data. Section 4 sums up the main findings of the studies.

\section{Method}

\subsection{Research Questions}

This paper compares LIFE metaphor in Chinese and English based on CMT. The research questions that guided the study are as follows. 
1) What are the universalities of LIFE metaphor between American and Chinese?

2) What are the variations of LIFE metaphor between American and Chinese?

3) What factors cause the universalities and variations in choosing a source domain?

\subsection{Data Source}

In order to compare the similarities and differences of LIFE metaphor in Chinese and English, we need to investigate what people say in actual language practice rather than what we think they would say in our minds. Thus it is necessary to build a database from an authoritative national corpus to increase the reliability of the study. Moreover, the two corpora should be similar in size, style, and established time for the sake of conducting the exhaustive and contrastive study. Therefore, the data collected in this paper comes from two large-scale corpora, Center for Chinese Linguistics, Peking University (henceforth CCL), and Corpus of Contemporary American English (henceforth COCA). The links for the online free search engines are as below: http://ccl.pku.edu.cn:8080/ccl_corpus/index.jsp (CCL) and https://www.english-corpora.org/coca/ (COCA).

CCL is a sizeable online corpus containing 700 million Chinese characters, developed by the Center for Chinese Linguistics, Peking University. It is composed of two subcorpora: the Ancient Chinese Corpus and the Modern Chinese Corpus. The data collected in this paper only comes from the Modern Chinese Corpus. Apart from the extensive collection, it has comprehensive coverage of data from newspapers, literature works, translation, academic works, movies, TV programs, internet to spoken materials, etc. CCL offers free online access for users. It is widely used by researchers on language, Chinese education, and language use in society.

COCA is the most extensive free English corpus and the first large-scale balanced American English corpus. It was founded by Professor Mark Davies in Brigham Young University and officially launched in 2008. COCA consists of 450 million words of text, which includes five different genres: spoken language, novels, popular magazines, newspapers, and academic articles. Each genre accounts for $20 \%$ of the corpus. The five genres are expanding at an annual rate of 200 million words to ensure the timeliness of corpus content from 1999 to 2012. The corpus is updated once or twice a year. Therefore, COCA is considered to be the most appropriate English corpus to observe the current development and change of American English.

Both of the corpora are general and monolingual. "General" means that the data is not restricted to any specific genre or style, but data from all kinds of fields. As for monolingual, it means that the data is from a specific language, such as American English or Chinese. Therefore, the reliability and comparability of data are assured.

\subsection{Data Collection}

The main problem that needs to be focused on is how to identify and extract LIFE metaphor from the corpus data. But before that, it is necessary to explain how we search on the two online corpora. LIFE has many synonyms in Chinese and English, such as "being” and "living” in English and “生活”, “活着” in Chinese. These words sometimes also express how we conceptualize and cognize life. In this paper, all the examples are only extracted by searching out “人生 rensheng" in CCL and "LIFE IS" in COCA due to the limitation of time and energy. The scope of extracting examples in both corpora should be the same styles. Thus data in this paper are not limited to any genre.

The English list of "LIFE IS" is easy to obtain because there are spaces between English words. We enter "LIFE IS" by using the searching function of "Collocates" in COCA to get the results and save the list. However, here are some restrictions that need to be mentioned in this process. Considering that life is usually conceptualized metaphorically as a noun, the head of the following six words is limited to nouns. Due to limits of time and energy, those with less than three occurrences in the database will not be analyzed. There are no restrictions on other options. Therefore, only the first 500 hits (listed by frequency) are chosen for analysis. As a result, there are 4761 examples in total, and only 629 examples are sentences with LIFE metaphor after extracting.

Comparatively, the Chinese list of “人生 rensheng" is not quite easy, because there is no word segmentation in Chinese sentences. Moreover, data in CCL are raw materials without any POS (part of speech) tagging. When we enter “人生 rensheng” in CCL, undesirable results like “个人生活 (personal life)”, “令人生气了 (irritating)”, etc. might appear. Human labor is needed to wipe out the undesirable results. In this paper, each example with “人生 rensheng" is checked one by one to eliminate the undesirable results and find out the sentences with life-metaphor. The Chinese list of “人生 rensheng” is obtained by typing “人生 rensheng” directly in CCL without any specific restrictions. As a result, there are 33448 examples in total, and only 5501 examples are sentences with LIFE metaphor after extracting. Though it seems to be a heavy workload, our native language being Chinese makes it easier for us to identify the metaphorical life sentences. 


\subsection{Identification of Metaphor}

After extracting data of LIFE from CCL and COCA, the next step is to identify the LIFE metaphor among these linguistic examples. To increase the credibility of the identification of metaphor, we adopted the method of MIP (Metaphor Identification Procedure). It is proposed by Pragglejaz Group (2007) in order to identify the metaphorical words in discourse. The main points of MIP can be summarized as follows. 1) Read the entire text to understand its general meaning. 2) Divide the whole text into several lexical units. 3) Find out the contextual meaning and lexical meaning of each lexical unit. 4) Compare the contextual meaning and the lexical meaning of each lexical unit. If the contextual meaning is in contrast with the lexical meaning, but can still be understood in terms of it, this lexical unit is metaphorical. Otherwise, it is literal. In order to illustrate MIP, we can use the words in bold in the following sentence as an example.

(1) ... but mainly the fact that at last, his life is on a good track.

A reading of the whole sentence, step 1, reveals that it is concerned with a person's life is finally heading in the right direction.

In step 2, the lexical units among the above bold words are identified as follows. Slashes are used here to indicate boundaries.

\section{life/is/on/a/good/track/}

In step 3, we outline our decisions for each lexical unit and then determine whether the lexical unit is metaphorically used in the context of this text in step 4.

\section{life}

(a) contextual meaning: In this context, "life" refers to this person's period from his birth to his death

(b) basic meaning: One of the basic meaning of "life" is the period between somebody's birth and death.

(c) contextual meaning versus basic meaning: The contextual meaning is closely related to the literal meaning.

(d) metaphorically used? No.

\section{is}

(a) contextual meaning: In this context, "is" introduces the person's possible state in the future.

(b) basic meaning: As a linking verb, "is" refers to have the quality of being;

(c) contextual meaning versus basic meaning: The contextual meaning is closely related to the literal meaning.

(d) metaphorically used? No.

\section{on}

(a) contextual meaning: In this context, the preposition "on" indicates spatial orientation. That is, it introduces a noun phrase (a good track) by indicating where the future life state will be.

(b) basic meaning: The basic meaning of "on" can be used to show direction

(c) contextual meaning versus basic meaning: The contextual meaning is closely related to the literal meaning.

(d) metaphorically used? No.

\section{a}

(a) contextual meaning: In this context, "a" is an indefinite article that performs the grammatical function of indicating indefinite reference.

(b) basic meaning: The indefinite article "a" does not have a more basic meaning.

(c) contextual meaning versus basic meaning: The contextual meaning is the same as the literal meaning.

(d) metaphorically used? No.

\section{good}

(a) contextual meaning: In this context, "good" indicates that this person's choice is maybe the most right for his future life path.

(b) basic meaning: One of the basic meanings of the adjective "good" refers that it is most suitable or right for a particular purpose.

(c) contextual meaning versus basic meaning: The contextual meaning is closely related to the literal meaning. 
(d) metaphorically used? No.

\section{track}

(a) contextual meaning: In this context, "track" indicates the developing mode and direction of this person's life.

(b) basic meaning: The basic meaning of "track" refers to a rough and unpaved road or path. There is some direction for people to follow.

(c) contextual meaning versus basic meaning: The contextual meaning contrasts with the basic meaning, but can be understood by comparison with it. We can understand the general direction of the person's future life path in terms of real direction.

(d) metaphorically used? Yes.

To sum up, one out of the six bold words is recognized as metaphorical. "Track" is originally an element of the JOURNEY frame. It is used to refer to the development and direction of one's future life. In conclusion, this sentence contains LIFE IS A JOURNEY metaphor. Our explanation of the application of MIP to lexical units is intended to demonstrate how the procedure works and how the researchers make decisions in judging whether the examples in the corpus are used metaphorically. In order to increase the data credibility, this paper conducts three times throughout check repeatedly.

\section{Results}

\subsection{Frequency of LIFE Metaphor in CCL and COCA}

In the first step, we identify and extract LIFE metaphor utilizing the method of MIP in the two large corpora. In sum, there are 5501 Chinese LIFE metaphor in CCL and 629 English LIFE metaphor in COCA. Specific data are shown as follows.

Table 1. The number of sentences containing LIFE metaphor

\begin{tabular}{llll}
\hline & Total sentences & Life-metaphor sentences & Percentage \\
\hline “人生 rensheng” (in CCL) & 33448 & 5501 & $16.45 \%$ \\
LIFE (in COCA) & 4761 & 629 & $13.21 \%$ \\
\hline
\end{tabular}

According to the data, it can be found that both English and Chinese have a significant number of LIFE metaphors, but the frequency of “人生 rensheng” metaphor in CCL is higher than LIFE metaphor in COCA. In other words, LIFE metaphor is a pervasive phenomenon both in CCL and COCA, but conceptual metaphors denoting LIFE is more pervasive in Chinese than English.

\subsection{Universalities and Variations of the Conceptual Metaphors Denoting LIFE in CCL and COCA}

After the identification of LIFE metaphor in CCL and COCA, it can be seen that LIFE metaphors are relatively abundant in English and Chinese. In order to find out how similar and different they are, we draw up a list of the ten most frequently occurring conceptual metaphors in CCL and COCA. The detailed data can be shown in the following tables.

Table 2. The ten most frequent Chinese conceptualizations of LIFE in CCL

\begin{tabular}{llll}
\hline No. & Metaphor & Tokens & Percentage \\
\hline 1 & JOURNEY/VOYAGE & 3655 & $66.44 \%$ \\
2 & OPERA & 277 & $5.04 \%$ \\
3 & FOOD & 227 & $4.13 \%$ \\
4 & WAR & 141 & $2.56 \%$ \\
5 & MUSIC & 104 & $1.89 \%$ \\
6 & DREAM & 89 & $1.62 \%$ \\
7 & BOOK & 87 & $1.58 \%$ \\
8 & TRAGEDY & 84 & $1.53 \%$ \\
9 & MOUNTAIN-CLIMBING & 69 & $1.25 \%$ \\
10 & PAINTING & 55 & $1.00 \%$ \\
& SUB-TOTAL & 4788 & $87.04 \%$ \\
& TOTAL & 5501 & $100.00 \%$ \\
\hline
\end{tabular}


Table 3. The ten most frequent English conceptualizations of LIFE in COCA

\begin{tabular}{llll}
\hline No. & Metaphor & Tokens & Percentage \\
\hline 1 & JOURNEY/VOYAGE & 118 & $18.76 \%$ \\
2 & GAME & 39 & $6.20 \%$ \\
3 & GIFT & 36 & $5.72 \%$ \\
4 & DREAM & 34 & $5.41 \%$ \\
5 & FOOD & 27 & $4.29 \%$ \\
6 & STRUGGLE & 26 & $4.13 \%$ \\
7 & WAR & 24 & $3.82 \%$ \\
8 & STORY & 22 & $3.50 \%$ \\
9 & MOVIE/FILM & 22 & $3.50 \%$ \\
10 & BOOK & 17 & $2.70 \%$ \\
& SUB-TOTAL & 365 & $58.03 \%$ \\
& TOTAL & 629 & $100.00 \%$ \\
\hline
\end{tabular}

The top three Chinese source domains in descending order are JOURNEY/VOYAGE, OPERA and FOOD, as opposed to the American JOURNEY/VOYAGE, GAME and GIFT. The JOURNEY metaphor ranks the most frequent conceptualization of LIFE on both Chinese and English lists. They both emphasize the purpose of life and difficulties in life. Accordingly, Chinese conceptualize LIFE as achieving one's life goal and a road full of hardships. At the same time, Americans describe life as striving to reach our destination in life and a series of constantly bifurcating paths. Regarding the second most frequently used source domain for life on the respective lists, Chinese write about life as an OPERA with roles, curtains and stage, as opposed to the Americans, who write about life as a GAME and they try their best to make life better within the limits and rules of the game. As for the FOOD metaphor in Chinese, its different flavors in life are mentioned (e.g., sour, sweet, bitter, spicy and salty), whereas Americans view life as a GIFT from the creator (e.g., every life is an individual gift from God).

In other words, where Chinese talk about OPERA in connection with life, Americans talk about GAME, and where Chinese view life as FOOD, Americans view it as a GIFT. They both conceptualize life as JOURNEY.

\subsubsection{Universality of the Conceptual Metaphors Denoting LIFE in CCL and COCA}

The first similarity is that both of them are systematic and they both construct the concept of LIFE from different perspectives. These metaphorical conceptualizations of LIFE reflect the connotation of LIFE from different aspects. As a result, the metaphorical network system about LIFE is formed, which also embodies the systematization of language to some extent. Although these different source concepts emphasize and explain the target concept of LIFE differently, their purposes are the same - to help people understand LIFE systematically in different ways. They are not contradictory but unified.

Though English and Chinese are two completely different language systems, the way they conceptualize the concept of LIFE cross with each other. A glance at Table 2 and Table 3 makes it evident that the Chinese metaphorical conceptualizations of LIFE are close to that of American: five out of the ten top metaphors in the respective data sets are shared (JOURNEY/VOYAGE, FOOD, WAR, and DREAM, BOOK).

The JOURNEY metaphor is a very popular conceptualization, as it surfaced as the most frequent metaphor in both corpora, accounting for $66.44 \%$ of the CCL data and $18.76 \%$ of the COCA data. This is a conventional metaphor widely used by scholars abroad and at home. All journey frames consist of three major components: PEOPLE (e.g., traveler), PATH (e.g., starting point/endpoint of the road, destination, crossroad, direction, turning point), and ENTITIES (e.g., obstacles, compass). To understand LIFE as a JOURNEY is to understand a mapping between the structure of the JOURNEY domain and the structure of the LIFE domain. For example, we can understand LIFE IS A JOURNEY metaphor by the correspondences between a traveler and a person living the life, the traveled path and the course of a lifetime, the endpoint of journey and death, the crossroad/direction and the choices in life, obstacles and difficulties in life, and so on. Examples are as follows.

(1) a. 如果从小接受的是金钱至上的观念, 长大后很难正确对待金钱, 难免在[人生]的道路上迷失方向。

If we were taught to be money-oriented since we were young, it would be difficult for us to treat money correctly when we grow up, and we will inevitably lose our way on the road of life.

b. 最后, 青少年正处于[人生]的十字路口, 他们面临着升学和就业的选择。

Lastly, teenagers are at the crossroads of their lives. They are faced with the choice of furthering their study or finding a job. 
c. ... reverberating throughout with the disturbing recognition that each passage in life is a passage toward death.

d. Finally, she says, she feels as if her life is back on track.

In the examples above, LIFE is conceptualized as JOURNEY. People start this journey since they were born and end it when they die (1c). In our life path, we need to make choices when we come to the crossroad. Each choice signifies one different direction of life. In (1b), adolescence is regarded as the crossroad in a teenager's life path. Teenagers ought to make important decisions at that time, which will decide the future direction of their life. Only when people recognize the right direction and insist on this direction (1d) can they stop being lost (1a) and finally get to the destination of life.

WAR as a source domain for LIFE ranks the fourth in CCL and the seventh in COCA. In a war, fighters meet enemies and face challenges. They have to fight with weapons under the instruction of commander in the battleground. Likewise, people encounter the same in life. Take the cancer patients as an example, the fighter is the patient, the enemy for them is cancer, and the commander is the doctor. Examples for LIFE IS A WAR are as follows.

(2) a. 而且语言本身就相当的好战, 它通常被当成“[人生]斗争的武器”, 被当成短刀或者七首。

And language itself is quite belligerent. It is usually regarded as "the weapon in the struggle of life", such as a knife or dagger.

b. [人生]没有几场主力战好打。

There is not much decisive battle in life that is easy to fight.

c. Every man at some point in his life is going to lose a battle.

d. He identifies with All Quiet on the Western Front, he wrote, because prison life is like war: "Each man fights his own battle."

In each war, fighters should use weapons to defend themselves. In the war of life, language is the weapon for people to fight (2a). The weapon may be a knife or a dagger, which is short but aggressive enough. Every man should fight his own battle in order to survive $(2 \mathrm{~d})$. Some battle is crucial and will decide the future direction of people's road. So these decisive battles may be difficult to win (2b). But sometimes losing a war may be a better choice in the life war $(2 \mathrm{c})$.

DREAM is the sixth most frequent metaphorical conceptualization of LIFE in CCL and the fourth in COCA. People always say life is like a dream. On the one hand, they want to emphasize the shortness of life; on the other hand, they suggest that some of the people's life experiences have long disappeared in memory, while others are still fresh as if it happened yesterday. Some derived metaphors are as follows.

(3) a. 至今一直独身的她觉得[人生]简直像一场梦。

She has been single so far and feels that [life] is like a dream.

b. 《念奴娇・赤壁怀古》: “[人生]如梦, 一尊还酹江月。”

Recalling Antiquity at the Cliff: "Life is like a dream. Yet with this cup of wine, let me pour a libation to the moon on the river."

c. "Life is but a dream." Judy ends.

d. Cause life is short as a dream, once you stop and ponder it.

As shown above, life is really like a short dream (3a, 3b, 3c, 3d). It is frequently used since ancient times, such as the LIFE IS A DREAM metaphor in the poetry of Recalling Antiquity at the Cliff (3b).

\subsubsection{Variation of the Conceptual Metaphors Denoting LIFE in CCL and COCA}

Fauconnier (1994, p. 10) observes that there appears to be a lot of variation at different levels: "This implies possible variation from community to community, from context to context, from individual to individual". There is no doubt that metaphor is a universally attested cognitive phenomenon that fundamentally shapes the conceptual structures and linguistic expressions of all languages, in one way or another. It does not follow from this sort of universality, however, that all human languages must avail themselves of it in the same way.

While many of the metaphors are shared on both lists (five out of the top ten metaphors are shared), these shared metaphors rank quite differently in the respective lists. FOOD, for example, figured as only the fifth most popular source domain in COCA, while it is the third most frequently used metaphor in CCL. Further, WAR 
ranks fourth on the Chinese list, while it is the seventh item on the American list. In other words, shared conceptual metaphors may vary cross-culturally in the frequency of their use (Kövecses, 2015, p. 13).

LIFE IS A GAME metaphor ranks the second in COCA, whereas it does not even show up in the top ten metaphor list in CCL. Many things in life are unpredictable. Just like games, we cannot predict whether we will win or lose. Specific games show up relatively frequently in COCA, these being chess games, gambling games, card games and so on. LIFE is conceptualized as a GAME by mapping the relevant structure of a GAME to the concept of LIFE and using specific words in games to talk about life. In a game, there are the participants, the race for the participants to participate, and the final goal (e.g., success or failure) and rules. The corresponding metaphorical expressions are as follows.

(4) a. For example, one participant stated that, "Life is a roulette game. This metaphor helps me to understand that things always change."

b. I have come to the conclusion that life is like a card game. You are dealt five cards and have no control.

In the above example, life is understood as a gambling game, which is in the form of a roulette game in (4a) and a card game in (4b). Things in a gambling game are changing all the time, we can neither predict the result nor take everything under control. Life is just like a gambling game that is always unpredictable and uncontrollable. Life is mostly conceptualized as dice games or card games in American English expressions, which belong to the more active types. Players ought to make decisions constantly and assess the chances and risks while playing. Schmidt and Brdar (2012) suggest that these metaphorical linguistic expressions reflect that Americans have a more active attitude towards life and hope to remain in control of their lives.

On the contrary, the frequency of the metaphor LIFE IS A BOOK is higher in Chinese than in English. BOOK as a source domain for LIFE figures the seventh in CCL, while it ranks the tenth in COCA. Everyone's book of life is unique in the world. As long as life continues, this book will be written down by him every day, page by page. The LIFE IS A BOOK metaphor activates a series of correspondences (i.e., metaphorical mapping) between the source domain of BOOK and the target domain of LIFE, such as the author of the book- the person in life, the content of the book - life experience, turning pages - things experienced, new pages - new life, and so on. Given in (5) are some examples.

(5) a. 你说得很好: [人生]是一部大书。

You said it very well: life is a big book

b. 也就是从这时起, 他开始翻开[人生]新的一页。

From this moment on, he began to turn a new page in [life].

c. Your life is a book, and every year is a page.

d. Life is a blank book that every person fills with one's will and experiences.

Example (5a) describes LIFE as a big book, which has many pages. In (5c), every year is a different page in the life book. To start a different life experience is to turn a new page in life, as found in (5b). Example (5d) presents that everyone can write his unique life book with his own will and experiences.

The potentially universal metaphors may also display variation in their specific details. Some authors (see especially Kövecses (2005) have argued the existence of two different levels of conceptualization: a generic level of human embodied cognition and a more specific level of elaboration of these universal schemas. Conceptual variation, according to these researchers, would be limited to the second level. For example, although both English and Chinese use the same source domain of FOOD for LIFE, there are still subtle differences. That is, their connotation may be different. Though FOOD as a source domain is popularly used both in American and Chinese metaphor for LIFE, their emphasis is different. FOOD is a higher-level concept with certain basic- or subordinate-level concepts being categorized under it. Data in CCL describe life as FOOD with five different flavors. Chinese emphasize the harmony of five flavors. Food with different flavors brings people different taste, which is exactly as the different feelings that different situations in life bring people. Nevertheless, data in COCA mostly liken life to a box of chocolates. This metaphor means that "you never know what you'll get". In fact, it is a quote from the movie Forrest Gump (1994). As the main protagonist says, "Mama always said life was like a box of chocolates. You never know what you're gonna get". This metaphor might indicate the effect of American popular culture on American's conceptualization of LIFE. Here are some examples.

(6) a. “人们常说, [人生]如五味瓶, 甜、酸、苦、辣、咸, 这几年我算全尝到了。现在我很想在其它事业 上拓展一下, 在新的领域里继续品味[人生]的滋味。” 
"People often say that [life] is like a five flavored bottle which is sweet, sour, bitter, spicy and salty. I have tasted all the five flavors these years. Now I'd like to expand my career and continue to savor the flavors of life in a new field.

\section{b. [人生]嘛, 酸甜苦辣咸, 本来是五味调汤。}

Life is a five flavored soup, which is sweet, sour, bitter, spicy and salty.

c. This year, we learned from the movie, Forrest Gump, that life is like a box of chocolates-you never know what you're going to get

d. So it has a happy ending? You like it? Life is a good box of chocolates? TOM HANKS: It is pretty good.

Flavor is the overall feeling that food brings to people, which is reflected in particular as sweet, sour, bitter, spicy and salty. In (6a) life is likened to a five flavored bottle and in (6b) a five flavored soup. In (6c) and (6d), life is described as a box of chocolates. People may always be surprised by what they'll get.

LIFE IS FOOD metaphor reveals one case of metaphorical variation, where the roughly same metaphor is provided for the two languages, but one language shows a preference for how the metaphor is employed specifically.

There is another kind of metaphorical variation, which refers to the case where unique source domains are used for a specific target domain in different languages.

OPERA is a case where a unique source domain is used for LIFE in Chinese, which is the second most frequently conceptualization of LIFE in CCL, accounting for $5.04 \%$ of the total data. In the conceptual metaphor of LIFE IS AN OPERA, OPERA refers to all the traditional varieties of "Chinese opera" as a cover term, which is unique in the context of Chinese culture, represented by the prototype of Beijing Opera. This complex frame consists of three aspects: PEOPLE, PERFORMANCE and VENUE. It is worth noting that PERFORMER, OPERA and STAGE are the most salient conceptual elements in their respective aspects. In other words, they are the three "focal points" of all the elements in the frame. The STAGE consists of many components, such as an elevated platform, curtains, backgrounds, etc., which are salient in the CCL data. Here are some examples.

(7) a. 终于, [人生]的一个阶段落下帏幕. 有所得亦有所失.

Finally, a stage of life lowered its curtain. There are always gains and losses.

b. 在[人生]的舞台上, 我们每个人都是演员, 都在演绎着一个个独特的故事。

On the stage of life, each of us is an actor who is interpreting his own unique story.

In (7b), LIFE is conceptualized as an OPERA, where everyone leads their life as an opera and "plays their own roles" as "actors and actresses" in the "life stage". And "every actor/actress" is playing his own unique "script". In (7a), "curtains" are said to be opened or closed so as to start or end a particular event. There are different chapters in the life opera. Curtains are closed when one chapter ends, which is also the signal of the beginning of another chapter. Therefore, people are always in the struggle of losing something in the last chapter but gaining in the next.

The sister versions of LIFE IS AN OPERA should be LIFE IS A PLAY, LIFE IS A MOVIE, etc., which are the subversions at the specific level dominated by LIFE IS A SHOW at a generic-level (Kövecses, 2005). Lakoff and Turner (1989, p. 20) considered LIFE IS A PLAY as "an extraordinarily productive basic metaphor for life", which can be evidence in examples like it is curtains for him, that's not in the script, you missed your cue. PLAY as a source domain for LIFE ranks twelfth in COCA, accounting for $2.54 \%$ of the English data. It is represented and highlighted by the Shakespearean tradition in western culture. Though there are commonalities between plays, operas and movies, LIFE IS AN OPERA is the dominant subversions in Chinese, where OPERA refers to Chinese opera with Beijing opera as its prototype in the specific context of Chinese culture.

Table 2 and Table 3 are not simply two frequency lists of the most common source domains of LIFE that Americans and Chinese use. By contrary, "it suggests that American and Chinese have different concepts of life and the differences arise as a result of the different preferences in the use of largely overlapping source domains" (Kövecses 2005, p. 85). In other words, the available source domains to both Chinese and American linguistic communities are generally the same. However, some source domains are used more often in the respective linguistic communities, which results in people's different attitudes towards life. As a result, some conceptual metaphors gradually become more established and more entrenched.

\subsection{Factors Leading to the Universality and Variation}

Based on the above analysis, it can be found many similarities and differences in the conceptualization of LIFE 
in Chinese and English. Then the next question arises: what leads to the similarities and differences? This section is dedicated to talking about this question.

\subsubsection{Factors Leading to the Universality}

As results revealed above, five out of the ten top metaphors in CCL and COCA are shared. How is it possible that two such diverse languages and cultures share the same metaphors? Kövecses $(2005$, p. 35) has given some explanation for such commonalities. "It should come as no surprise that at least some conceptual metaphors can be and are found in many languages. If some kinds of conceptual metaphors are based on embodied experience that is universal, these metaphors should occur - at least potentially — in many languages and cultures around the world". In other words, the universal human experience between English and Chinese leads to the commonalities of LIFE metaphor. Embodiment as a general motivation should be understood in the broadest possible sense, extending fundamentally from the body to the immediate physical environment to the social and cultural environment.

People around the world may share common bodily experience that originates the same physical structures or physiological phenomenon.

The source domains for LIFE based on bodily experience cover aspects of human vision, hearing, taste and smell, such as his colorful life, different songs of life, taste the sweetness of life, the smell of life. In English and Chinese, LIFE metaphor based on direct body experience are almost all-round.

For both Chinese and Americans, dream is a normal physiological phenomenon that everyone is familiar with. Everyone has had dreams. Dreaming is a spontaneous physiological activity that occurs at a certain stage of consciousness during sleep. Although the duration of dreaming is very short, the content of dreams is varied. People may remember it vividly and become happy when they dream something pleasant while they would like to forget it as soon as possible when they dream something unpleasant. The same is true of life. A person's life is very short. But he will encounter many things in his life, including both the pleasant things and unpleasant things. People are always inclined to forget all the unpleasant things. Based on the similar physiological experience, both Chinese and American people understand the abstract term of LIFE by means of the more familiar term of DREAM.

Human beings can also perceive the concept of LIFE on the basis of the common knowledge and experience about the world. Taking people's experience on a journey as an example, everyone in the world may have been on a long or short trip. There is some destination for the traveler on a journey. He may encounter difficulties and setbacks and be confused at a crossroad. His different choices will determine the different paths and even the different futures for him. Sometimes he may deviate from the right path. And an advanced plan may save him big trouble. But no matter how difficult it is, he will finally get to the end of the journey directed by the destination. Due to people's common experience of the journey, there exists a shared metaphorical conceptualization of LIFE: LIFE IS A JOURNEY. The LIFE IS A JOURNEY metaphor reflects similar Chinese and English life outlook - people should have a purpose in their life. Without purpose, they may not be able to choose at a life crossroad and easily fall into the wrong life path. Planning our life initiatively can ensure a smoother life. People shouldn't just accept their life passively.

Embodiment is also used to refer to the social and cultural context in which the body, cognition, and language are perpetually situated (Rohrer, 2007, p. 29). The social-cultural experience is another important factor for the commonness between Chinese and English LIFE metaphor. In the long course of human history, people were always haunted by wars. To some extent, the history of human development is accompanied by the history of war. In the history textbook of any country, in addition to the records of the development of human civilization, most of them are used to describe various wars. From the perspective of culture, war plays an important role in the culture. Three quarters of China's four masterpieces are closely related to war. Through that the strong position of war in culture can be seen clearly. War is also one of the focuses in world news reports. Many films that won awards at Oscars took the war as their theme, such as, Gladiator, Saving Private Ryan, Schindler's List, etc. In the history of Chinese films, there are countless films with the themes of the war of liberation, the Korean War and more self-counterattacks. Based on such similar social-cultural experience, many linguistic expressions originating from the conceptual metaphor of LIFE IS A WAR are found in Chinese and English. In a war, people in two or more parties compete with each other. They use various weapons and tactics for the triumph. People in life also use "weapons" in competition, which are mostly technology, talent, etc. They also apply strategy in life. WAR as a source domain for LIFE generally takes its metaphorical meaning, which refers to a war without smoke against self, competitors and various difficulties. The mapping between the two domains is based on the cognitive similarity of both being highly competitive. Furthermore, this shared metaphor LIFE IS A WAR 
reflects a similar life outlook in Chinese and English: life is full of competition; People ought to adopt the appropriate "weapons" and strategies in order to win.

To sum up, the above research shows that there are many similar conceptual metaphors about LIFE between China and America. These universalities result from similar bodily experiences originating from the physical structure and physiological phenomenon, common knowledge and experience about the world, social and cultural experience. In other words, embodiment is the main force for the universality of LIFE metaphor.

\subsubsection{Factors Leading to the Variations}

There are universal metaphors that are built by human being's sharing of many bodily experiences. But this universal bodily basis is not utilized in the same way across different cultures. The universal experiential basis does not necessarily lead to the universally equivalent metaphorical conceptualization. Then what are the motivations for the differences in the metaphorical conceptualization of the same concept across languages and varieties?

As discussed above, there may be cross-cultural differences in the frequency of use of shared conceptual metaphors (e.g., WAR, FOOD, DREAM). In addition, the potentially universal metaphors may display variations in their specific details (e.g., FOOD). This happens because people in different cultures use cognitive abilities in different ways. Finally, many conceptual metaphors are unique to specific cultures or sets of cultures (e.g., OPERA in Chinese) on account of the differences in factors such as social and cultural backgrounds, history, or human concerns that characterize these cultures (Kövecses, 2015).

Kövecses (2005, pp. 231-232) holds that factors responsible for conceptual metaphor variation can be divided into two categories: differential experience and differential cognitive preferences or styles. In other words, on the one hand, many of our metaphors are different, which are caused by human's different experiences. On the other hand, the different metaphors result from our different cognitive preferences or styles that we use to create abstract thought. The various subcases of differential experience include awareness of context, differential memory (the role of history), differential concerns and interests. Each of them also has subdivisions. For example, the awareness of context includes the physical environment, social context, cultural context and the awareness of the communicative situation. Differential memory is the memory of events and objects shared by a community or that of a single individual, and differential concerns and interests refer to the general attitude of a group or an individual to act in the world.

Human language is not just a cognitive but also a social and cultural artifact that does not exist in a vacuum. According to Naomi Quinn (1991), cultural models play a key role in our understanding of the world and our selection of metaphors. Cultural models are presupposed, taken-for-granted models of the world that are widely shared (although not necessarily to the exclusion of other alternative models) by the members of a society and that play a central role in their understanding of that world and their behavior in it (Holland \& Quinn, 1987, p. 4). Kövecses (2010) has noted that the effect of various kinds of context on metaphorical conceptualization is a crucial aspect of the recruitment of conceptual materials for metaphorical acts and expressions. Cultural context can be one of the crucial factors for the metaphorical variation. It refers to the unique and salient concepts and values that characterize particular (sub)cultures - together with the governing principles of a given culture or subculture (Kövecses, 2015). As JOURNEY is used to construct LIFE in both Chinese and English, their understanding of death as the end of the journey is different owing to their different religion. Religion is a crucial component of culture. Buddhism, as an important religion in China, is a significant part of traditional Chinese culture. With its long history in China, it exerts great impact on people's daily life. Buddhism believes in "Samsara", which refers to the process of a continuous cycle of life and death. So the path in the life journey is a closed cycle. However, Christianity is the most important religion in America. Americans conceptualize the path in the life journey as a straight line rather than a cycle. Influenced by the different values between Buddhism and Christianity, cross-cultural variations occur in metaphorically conceptualizing LIFE as JOURNEY at a specific-level.

Variations in conceptualizing LIFE as DREAM can also be explained by the different religions. Though the metaphor LIFE IS A DREAM is popularly used in both Chinese and American data, this metaphor in Chinese culture not only emphasizes that life is short but also contains the thoughts of self-liberation and the peaceful attitudes towards setbacks, which are influenced by Chinese traditional Taoism and Buddhism. The Chinese allusion of Chuang-Tzu butterfly dream embodies the spiritual pursuit of absolute freedom regardless of difficulties and setbacks. This view has had a profound impact on the Chinese people for thousands of years.

In Chinese, the LIFE IS AN OPERA metaphor is in fact formulated within embodied and socioculturally-situated contexts. It taps into a specific frame of cultural knowledge about Chinese opera, which can trigger the mental 
images of its unique vocal and bodily artistic expressions, costumes, makeups and so on in the minds of Chinese people who are familiar with it. Chinese opera, the "national entertainment", has well-defined elements and relations among them, as well as well-defined patterns adopted by these elements and relations. Due to its well-structured form and prominent position in Chinese traditional culture, OPERA is an ideal source domain for LIFE in Chinese. The highly culture-specific Chinese opera is in stark contrast with Shakespearean plays or Western operas. As Yu (2011a, p. 626) points out: "While sharing some common properties of fruits at a more abstract level, at a concrete level an apple is an apple and an orange is an orange". Besides, GAME is more heavily used as a source domain for LIFE in COCA. Such variation can be accounted for by taking the American trait of being active in life into consideration. Americans are often said to be given to action rather than passivity. They are willing to get control of their lives and strive for a better future, just like competitors in games use strategies actively to gain success. LIFE IS GAME metaphor reflects American's outlook of being active rather than passive.

The social context, similar to the cultural context, can be extremely variable, which can also result in variations in the use of LIFE metaphor. Kövecses $(2005$, p. 233) suggests that social issues such as power relations and social pressure may exert an influence on the metaphorical conceptualization. The traditional concepts of "all walks of life, only reading high" "there is gold in the book, there is beauty in the book" still have a certain impact on the Chinese people. Many Chinese people regard learning as a way of making money. They strongly believe that "learning" is the only way for children to change their destiny. In addition, the popular exam-oriented education in China emphasizes the use of examinations and scores to measure the level of students. Students have to immerse themselves in the sea of books in order to pursue higher education and be successful. Under the background of great social pressure, students are encouraged to study and read. In contrast, there is not as much social pressure in the West as in China. Westerners put more emphasis on the cultivation of students' practical ability. Therefore, it makes sense why the LIFE IS A BOOK metaphor is more frequently used in Chinese than English.

As Radden and Panther (2004, p. 26) state: "Just as present-day human behavior is the result of past motivations, present-day language behavior (and we might add, the products of this behavior, language structures) is motivated by factors that were operative a long time ago but whose effects are still visible today". Differential memory is another aspect that influences differential experience which produces the differential metaphors. It refers to the memory of events and objects shared by a community or that of a single individual (Kövecses, 2015). "Memory" here means "history". It is called "memory" in that these events are remembered by the society/culture, group, or individual through its collective unconscious, which is embodied in language. Food is one of the most basic physiological needs of human beings that people cannot live without. So there is a shared metaphor for LIFE in Chinese and English: LIFE IS FOOD. However, Food is in a much more prominent position in China. For example, Chinese people often associate food with many daily events, such as greetings (e.g., have you eaten?), weddings and promotions. In addition, almost all traditional Chinese festivals revolve around the theme of "eating". The prominent position of food in the mind of Chinese people can be explained by its history. On the one hand, Chinese people are very fond of "eating", which is a reflection of the frequent famine in Chinese history that has made Chinese people suffer a lot. On the other hand, the ruling class in Chinese history was able to eat well and enjoy well. They pay much attention to the color, smell, and flavor of food, the complexity of food processing, and the rich meaning of food, which is beyond any other culture in the world. This history explain us why FOOD is the third popularly used source domain for LIFE in CCL with five flavors highlighted in the data.

Briefly, this section has investigated the factors for different metaphorical variations of LIFE from the following aspects: cultural context with religion as a subpart, social context under the influence of power relations and social pressure, and differential memory. The variations in the use of the JOURNEY, DREAM, OPERA, GAME metaphors are particularly influenced by cultural context, BOOK by social context (i.e., social pressure in Chinese), and FOOD by differential memory. In a word, the major driving force behind variations of LIFE metaphor is context.

\section{Conclusion}

With data collected from CCL and COCA, this research compared LIFE metaphor in Chinese and English and found out that there are both universalities and variations of LIFE metaphor in Chinese and English. Reasons for the universalities and variations are further summarized as follows.

On the basis of all the analysis above, it is obvious that the abstract concept of LIFE is systematically perceived in both languages in terms of more concrete concepts from different perspectives. Some similar conceptual metaphors are also found in Chinese and American corpus analyzed in the study, including LIFE IS A 
JOURNEY/VOYAGE, LIFE IS FOOD, LIFE IS A WAR, LIFE IS A DREAM, and LIFE IS A BOOK. Our results suggest that embodiment is the main force for the universality of LIFE metaphor in Chinese and English, which in the broadest sense includes (a) the common bodily (e.g., DREAM), (b) common knowledge and experience about the world (e.g., JOURNEY), and (c) social and cultural experience (e.g., WAR). The common life outlooks reflected by the LIFE IS A DREAM, LIFE IS A JOURNEY and LIFE IS A WAR metaphors are respectively that life is really short, we should have a clear and firm goal in life, and we must adopt appropriate tools and strategies in order to survive in the life battlefield.

Regarding the variations, there are cases where shared metaphors differ in the frequency of use (e.g., FOOD, WAR, DREAM, BOOK), potentially universal metaphors display variations in their specific details (e.g., FOOD), and unique source domains are used for specific culture (e.g., OPERA). The variations in the metaphorical conceptualization of LIFE in Chinese and English are mainly caused by (a) different cultural context with religion as a subpart (e.g., JOURNEY, DREAM, OPERA, GAME), (b) differential social context under the influence of power relations and social pressure (e.g., BOOK), and (c) differential memory (e.g., FOOD). In a word, the major driving force behind variations of Chinese and English LIFE metaphor is context. The cross-cultural variations in conceptualizing LIFE reflect different life outlooks. LIFE IS A DREAM in Chinese culture not only emphasizes that life is short but also contains the thoughts of self-liberation and the peaceful attitudes towards setbacks. LIFE IS A GAME reflects that Americans take a more active attitude towards life instead of accepting life passively.

However, the main constraints in mentioning the study should still be addressed. For one thing, this paper searches the target domain LIFE directly in each corpus. But there are lots of metaphorical expressions detonating LIFE that do not contain "LIFE IS" in English or “人生 rensheng” in Chinese. Thus, the results of LIFE metaphor may be not exhaustive. For another, though this paper adopts the MIP method to increase the credibility of results, much identification and classification are subjective to the researchers to some extent. Therefore, further research is necessary to adopt a more comprehensive and objective method in order to guarantee the results.

\section{Acknowledgments}

The study has been supported by the research project Corpus-Based Contrastive Study of LIFE Metaphor Variation in English and Chinese (18YY05) funded by Jiangxi Provincial Planning Office of Philosophy and Social Sciences in P. R. China.

\section{References}

Benczes, R., \& Ságvári, B. (2018). Where metaphors really come from: Social factors as contextual influence in Hungarian teenagers' metaphorical conceptualizations of life. Cognitive Linguistics, 29(1), 121-154. https://doi.org/10.1515/cog-2016-0139

Bochaver, A., \& Fenko, A. (2010). Metaphors in happy and unhappy life stories of Russian adults. Metaphor and Symbol, 25, 243-262. https://doi.org/10.1080/10926488.2010.510928

Bottomley, P. A., \& Doyle. J. R. (2006). The interactive effects of colors and products on perceptions of brand logo appropriateness. Marketing Theory, 6(1), 63-83. https://doi.org/10.1177/1470593106061263

Brdar-Szabo, R., \& Mario, B. (2012). The problem of data in the cognitive linguistic research on metonymy: A cross-linguistic perspective. Language Sciences, 34, 728-745. https://doi.org/10.1016/j.langsci.2012.04.012

Bystrov, Y. (2014). Fractal metaphor LIFE IS A STORY in biographical narrative. Topics in Linguistics, 14(1), 1-8. https://doi.org/10.2478/topling-2014-0007

Chen, J., \& Xie, S. (2015). Figure representation of Life metaphors in Shakespeare's four tragedies. Journal of Southwest University of Science and Technology: Philosophy and Social Sciences Edition, 32(1), 9-15.

Ching, M K. L. (1993). Games and play: pervasive metaphors in American life. Metaphor and Symbol, 8(1), 43-65. https://doi.org/10.1207/s15327868ms0801_3

Cross, T L. (2007). The changing life metaphor of gifted youth. Gifted Child Today, 30(1), 14. https://doi.org/10.4219/gct-2007-25

Fauconnier, G. (1994). Mental Spaces. Aspects of Meaning Construction in Natural Language. Cambridge: Cambridge University Press. https://doi.org/10.1017/CBO9780511624582

Fauconnier, G., \& Turner, M. B. (2008). Rethinking metaphor. In R. W. Gibbs (Ed.), The Cambridge Handbook of Metaphor and Thought (pp. 53-66). New York: Cambridge University Press. 
https://doi.org/10.1017/CBO9780511816802.005

Group, P. (2007). MIP: A method for identifying metaphorically used words in discourse. Metaphor and Symbol, 22(1), 1-39. https://doi.org/10.1080/10926480709336752

Hoffman, E., \& Acosta-Orozco, C. (2015). Life metaphor among Colombian leadership students: Core values and educational implications. College Student Journal, 49, 438-446.

Holland, D., \& Quinn, N. (Eds.). (1987). Cultural Models in Language and Thought. Cambridge: Cambridge University Press. https://doi.org/10.1017/CBO9780511607660

Huang, X. (2013). Cognitive study of life metaphors. Journal of Hubei University of Economics (Humanities and Social Sciences Edition), 3, 112-114.

Jäkel, O. (1995). The metaphorical conception of mind: "Mental activity is manipulation". In J. R. Taylor \& R. E. MacLaury (Eds.), Language and the Cognitive Construal of the World (pp. 197-229). Berlin: Mouton de Gruyter.

Johnson, M. (1987). The Body in the Mind. Chicago and London: The University of Chicago Press. https://doi.org/10.7208/chicago/9780226177847.001.0001

Johnson, M. (1992). Moral Imagination. Chicago: University of Chicago Press.

Katz, A. N., \& Taylor, T. E. (2008). The journeys of life: Examining a Conceptual Metaphor with Semantic and Episodic Memory Recall. Metaphor and Symbol, 23, 148-173. https://doi.org/10.1080/10926480802223051

Kövecses, Z. (1986). Metaphors of anger, pride, and love: A lexical approach to the study of concepts. Amsterdam: John Benjamins. https://doi.org/10.1075/pb.vii.8

Kövecses, Z. (1988). The language of love: The semantics of passion in conversational English. Lewisburg, PA: Bucknell University Press.

Kövecses, Z. (1990). Emotion concepts. Berlin and New York: Springer-Verlag. https://doi.org/10.1007/978-1-4612-3312-1

Kövecses, Z. (1994). Tocqueville's passionate "beast": A linguistic analysis of American democracy. Metaphor and Symbolic Activity, 9(2), 113-133. https://doi.org/10.1207/s15327868ms0902_2

Kövecses, Z. (2002). Metaphor: A practical introduction. New York and Oxford: Oxford University Press.

Kövecses, Z. (2005). Metaphor in culture: Universality and variation. Cambridge: Cambridge University Press. https://doi.org/10.1017/CBO9780511614408

Kövecses, Z. (2010). Metaphor: A practical introduction (2nd ed.). Oxford: Oxford University Press.

Kövecses, Z. (2015). Where metaphors come from: Reconsidering context in metaphor. Oxford: Oxford University Press. https://doi.org/10.1093/acprof:oso/9780190224868.001.0001

Kromhout, R., \& Forceville, C. (2013). Life is a journey: source-path-goal structure in the videogames "Half-Life 2", "Heavy Rain", and "Grim Fandango". Metaphor and the Social World, 3(1), 100-116. https://doi.org/10.1075/msw.3.1.05for

Lakoff, G. (1987). Women, fire, and dangerous things: What categories reveal about the mind. Chicago: University of Chicago press. https://doi.org/10.7208/chicago/9780226471013.001.0001

Lakoff, G. (1992). Metaphor and semantics. International Encyclopedia of Linguistics, 2, 417-419.

Lakoff, G. (1993). The contemporary theory of metaphor. In A. Ortony (Ed.), Metaphor and thought (2nd ed., pp. 202-251). Cambridge: Cambridge University Press. https://doi.org/10.1017/CBO9781139173865.013

Lakoff, G. (1994). What is conceptual system. In W. F. Overton \& D. S. Palermo (Eds.), The Nature and Ontogenesis of Meaning (pp. 41-90). Psychology Press.

Lakoff, G., \& Johnson, M. (1980). Metaphors we live by. Chicago: University of Chicago Press.

Lakoff, G., \& Johnson, M. (1999). Philosophy in the Flesh: The Embodied Mind and its Challenge to Western Thought. Basic books.

Lakoff, G., \& Turner, M. (1989). More than cool reason: A field guide to poetic metaphor. Chicago: University of Chicago Press. https://doi.org/10.7208/chicago/9780226470986.001.0001

Lan, L., \& Macgregor, L. (2009). Colour metaphors in business discourse. Language for Professional 
Communication: Research, Practice and Training, 11.

Langacker, R. W. (1987). Foundations of cognitive grammar: Theoretical prerequisites (Vol. 1). Stanford: Stanford University Press.

Li, Y., \& Li, J. (2009). A comparative study of the conceptual metaphor of LIFE. Journal of Changchun University of Science and Technology (Higher Education Edition), 12, 67-68, 73.

Liang, H. (2010). The conceptual metaphor analysis of LIFE IS DIET in Chinese. Journal of Capital Normal University, 3, 98-100.

McConnell, A., Bill, C., Dember, W., \& Grasha, A. (1993). Personality through metaphor: Optimism, pessimism, locus of control, and sensation seeking. Current Psychology, 12, 195-215. https://doi.org/10.1007/BF02686802

McMullen, L., \& Conway, J. (2002). Conventional metaphors for depression. In S. Fussell (Ed.), The verbal communication of emotions: Interdisciplinary perspectives (pp. 167-181). Erlbaum: Mahwah, NJ.

Miao, M. (2014). A corpus-based comparative study of life metaphors in English and Chinese. Master's thesis, Shanghai International Studies University, Shanghai, China.

Porat, R., \& Shen, Y. (2017). Metaphor: The Journey from Bidirectionality to Unidirectionality. Poetics Today, 38(1), 123-140. https://doi.org/10.1215/03335372-3716252

Quinn N. (1991). The cultural basis of metaphor. In J. W. Fernandez (Ed.), Beyond Metaphor: The Theory of Tropes in Anthropology (pp. 56-93). Stanford University Press.

Radden, G., \& Panther, K. (2004). Introduction: Reflections on motivation. In G. Radden \& K.-U. Panther (Eds.), Studies in Linguistic Motivation (pp. 1-46). Berlin \& New York: Mouton de Gruyter.

Rohrer, T. (2007). Embodiment and experientialism. In D. Geeraerts \& H. Cuyckens (Eds.), The Oxford Handbook of Cognitive Linguistics (pp. 25-47). Oxford: Oxford University Press.

Schmidt, G., \& Brdar, M. (2012). Variation in the linguistic expression of the conceptual metaphor life is a (gambling) game. In B. Mario, R. Ida \& Z. F. Milena (Eds.), Cognitive linguistics between universality and variation (pp. 271-292). Cambridge: Cambridge Scholars Publishing.

Winter, S. L. (1995). A clearing in the forest. Metaphor and Symbol, 10(3), 223-245. https://doi.org/10.1207/s15327868ms1003_5

Yu, N. (2009). Nonverbal and multimodal manifestations of metaphors and metonymies: A case study. In C. Forceville \& E. Urios-Aparisi (Eds.), Multimodal Metaphor (pp. 119-143). Berlin: Mouton de Gruyter.

Yu, N. (2011a). Beijing Olympics and Beijing opera: A multimodal metaphor in a CCTV Olympics commercial. Cognitive Linguistics, 22(3), 595-628. https://doi.org/10.1515/cogl.2011.023

Yu, N., \& Jia, D. (2016). Metaphor in Culture: Life is a Show in Chinese. Cognitive Linguistics, 27(2), 147-180. https://doi.org/10.1515/cog-2015-0080

Wen, A. (2018). A corpus-based comparative study of the conceptual metaphor LIFE IS A JOURNEY in Chinese and English. Master's thesis, Huazhong University of Science and Technology, Wuhan, China.

Wang Y. (2002). Philosophical basis of cognitive linguistics: experiential philosophy. Foreign Language Teaching and Research, 2, 82-89, 160.

Wang, Z. (2011). LIFE IS WINE-conceptual metaphor and Chinese wine culture. College English (Academic Edition), 1, 60-63.

Zhang, W., \& Liu, N. (2015). "Empirical Cycle" of Cognitive Linguistics Research. Foreign Language Research, $3,18-23,29$.

Zhang, X. (2016). A corpus-based comparative study of Chinese and English metaphors of LIFE. Master's thesis, Hunan University, Changsha, China.

Zheng, Y. (2012). A Contrastive Study of the Conceptual Metaphor of LIFE in English and Chinese. Journal of Chengdu University of Technology, 6, 68-72. 


\section{Copyrights}

Copyright for this article is retained by the author, with first publication rights granted to the journal.

This is an open-access article distributed under the terms and conditions of the Creative Commons Attribution license (http://creativecommons.org/licenses/by/4.0/). 